\title{
(2) OPEN ACCESS \\ Implementation of a cloud-based referral platform in ophthalmology: making telemedicine services a reality in eye care
}

\author{
Christoph Kern (D) , 1,2 Dun Jack Fu, ${ }^{1}$ Karsten Kortuem (D) , 1,2 Josef Huemer, ${ }^{1,3}$ \\ David Barker, ${ }^{4}$ Alison Davis, ${ }_{1}^{1}$ Konstantinos Balaskas, ${ }^{1}$ Pearse A Keane, ${ }^{1,5,6}$ \\ Tom McKinnon, ${ }^{7}$ Dawn A Sim ${ }^{1,5,6}$
}

- Additional material is published online only. To view please visit the journal online (http://dx.doi.org/10.1136/ bjophthalmol-2019-314161).

${ }^{1}$ Moorfields Eye Hospital, London, United Kingdom ${ }^{2}$ Department of Ophthalmology, University Eye Hospital, LMU, Munich, Germany

${ }^{3}$ Eye Departement, Tauernklinikum, Zell am See, Austria

${ }^{4}$ Rawlings Opticians, Purley, UK ${ }^{5} \mathrm{NIHR}$ Biomedical Research Centre Biomedical Centre, Moorfields Eye Hospital NHS Foundation Trust and UCL Institute of Ophthalmology, London, UK

${ }^{6}$ Institute of Ophthalmology, University College of London, London, United Kingdom BBig Picture Medical, London, United Kingdom

\section{Correspondence to}

Dr Dawn A Sim, Medical Retina Department, Moorfields Eye Hospital NHS Foundation Trust, London EC1V 2PD, UK: dawnsim@nhs.net

Received 28 February 2019 Revised 24 April 2019 Accepted 27 June 2019 Published Online First 18 July 2019

\section{Linked}

http://dx.doi.org/10.1136/ bjophthalmol-2019-315066

Check for updates

(C) Author(s) (or their employer(s)) 2020. Re-use permitted under CC BY-NC. No commercial re-use. See rights and permissions. Published by BMJ.

To cite: Kern C, Fu DJ,

Kortuem $\mathrm{K}$, et al.

$\mathrm{Br} J$ Ophthalmol

2020;104:312-317.

\begin{abstract}
Background Hospital Eye Services (HES) in the UK face an increasing number of optometric referrals driven by progress in retinal imaging. The National Health Service (NHS) published a 10-year strategy (NHS Long-Term Plan) to transform services to meet this challenge. In this study, we implemented a cloud-based referral platform to improve communication between optometrists and ophthalmologists.
\end{abstract}

Methods Retrospective cohort study conducted at Moorfields Eye Hospital, Croydon (NHS Foundation Trust, London, UK). Patients classified into the HES referral pathway by contributing optometrists have been included into this study. Main outcome measures was the reduction of unnecessary referrals.

Results After reviewing the patient's data in a webbased interface 54 (52\%) out of 103 attending patients initially classified into the referral pathway did not need a specialist referral. Fourteen (14\%) patients needing urgent treatment were identified. Usability was measured in duration for data input and reviewing which was an average of $9.2 \mathrm{~min}$ (median: $5.4 ;$ IQR: 3.4-8.7) for optometrists and $3.0 \mathrm{~min}$ (median: 3.0; IQR: 1.7-3.9) min for ophthalmologists. A variety of diagnosis was covered by this tool with dry age-related macular degeneration $(n=34)$ being most common.

Conclusion After implementation more than half of the HES referrals have been avoided. This platform offers a digital-first solution that enables rapid-access eye care for patients in community optometrists, facilitates communication between healthcare providers and may serve as a foundation for implementation of artificial intelligence.

\section{INTRODUCTION}

The prevalence of the most common retinal diseases, age-related macular degeneration (AMD) and diabetic retinopathy (DR), is rising in industrialised countries. In addition to demographic changes, this trend is also partly driven by growing numbers of patients with diabetes mellitus. ${ }^{1-3}$ This is increasing the workload in hospital ophthalmic units, which in 2018/2019 had the highest number of outpatient attendances within the National Health Service (NHS) in the UK with 7.6 million patients annually. ${ }^{4}$ The service provision capacity is threatened by a low number of ophthalmologists per capita in the UK, which is further exacerbated by an expected growth of the population over 60 years at twice the rate of the profession. ${ }^{5}$

People aged below 16 or above 60, with diabetes or a family history of glaucoma are eligible for a free eye test within the NHS every 2 years. ${ }^{6}$ The Opticians Act 1989 obligates UK optometrists to refer any incidental eye abnormality detected during an NHS eye test to a Hospital Eye Services (HES) unless they provide a sufficient disease description including medical advice to the patient. ${ }^{7}$ With the introduction of advanced imaging devices as optical coherence tomography (OCT) and ultra-wide field imaging (UWFI), detection rates of asymptomatic retinal conditions and therefore specialist referrals have drastically increased. ${ }^{8}$

Cameron et $a l^{9}$ demonstrated that that more than a third of optometric referrals within the NHS did not need specialist consultancy. ${ }^{9}$ They also reported a reduction in these unnecessary referrals following introduction of an electronic referral system containing images sent as email attachments. This accentuates the importance of communication between optometrists and HES within the NHS, especially addressing imaging data as reported by the British Broadcasting Corporation (BBC) in 2016. ${ }^{10}$ Improved communication and data sharing could counteract the increasing pressure on HES by reducing unnecessary referrals.

The aim of this pilot study is to report the implementation and initial results of a cloud-based referral platform to medical retina HES, which was developed to overcome the increasing demand on scarce ophthalmologist services by improving communication between opticians and ophthalmologists.

\section{MATERIAL AND METHODS}

\section{Study setting and design}

In this retrospective cohort study, data from a cloudbased referral platform provided by Big Picture Medical (London, UK) was evaluated. All patients were referred to the medical retina service of Moorfields Eye Hospital, Croydon (NHS Foundation Trust, London, UK). This work was registered with the Service Improvement Department of Moorfields Eye Hospital and complies with the criteria defined in the Declaration of Helsinki. Before sharing data within the cloud, a mandatory consent for company policies and data processing was taken. An optional consent form for inclusion of de-identified clinical information including medical images 
for the purposes of medical education, assessment and research was offered to all patients. Participating optometrists practised at six sites of Rawlings Opticians (Purley, Surrey, UK) spread over South-East England in Alresford, Caterham, Chandler's Ford, Croydon, Purley and Winchester. Observation period spanned from April 2018 to January 2019. The rollout of the platform started in Rawlings Croydon Caterham and Winchester in early 2018, followed by Chandler's Ford, Purley and Winchester in July 2018.

\section{Data source}

Each examination at the attending optician was performed by trained optometrists and comprised clinical data, an OCT scan (Nidek RS-3000 advance-2, Nidek, Tokyo, Japan) and a $45^{\circ}$ colour fundus photo centred on the macula. Clinical data included history of presenting complaint, best corrected visual acuity (BCVA) reported in Early Treatment Diabetic Retinopathy Study (ETDRS) letters and intraocular pressure. If visual acuity was quantified using a Snellen chart, ETDRS letters were extrapolated following an established method. ${ }^{11}$ After gaining informed consent, clinical and scan data were uploaded to the cloud-based referral software for further assessment by a consultant ophthalmologist.

\section{Participants}

The participating optometrist were instructed to refer all presumably retinal referrals via the platform. Initial triage took place by the optometrist and other referrals like glaucoma, cataract or anterior segment conditions were excluded and sent through the conventional general ophthalmic services (GOS) pathway defined by the NHS. ${ }^{12}$ Inclusion criteria of this study were as follows: all patients must have attended an eye examination at the contributing opticians; an optometrist must have assessed a patient and determined them to meet the criteria for a conventional retinal HES referral; patients history, clinical findings and retinal imaging must have been taken and uploaded to the referral platform; referral refinement had to be carried out by a consultant ophthalmologist. Patients were excluded from this study if relevant clinical information or imaging data were missing on the platform server. Moreover, patients had the option to opt for their depersonalised data to not be included in research and/or to be referred by the conventional GOS pathway.

\section{Study outcomes}

To assess the reduction in referrals achieved by this platform, the main study outcome was the result of the referral refinement carried out by a consultant ophthalmologist classified into:

- 'Urgent referral' (HES appointment $\leq 4$ weeks): all causes of choroidal neovascularisation including age related macular degeneration and myopia, referable oedema as in diabetic maculopathy and subretinal fluid as in central serous chorioretinopathy.

- 'Routine referral' (HES appointment within 18 weeks referral to treatment time defined by the $\mathrm{NHS}^{13}$ ): all other non-urgent cases that needed further diagnostic or specialist evaluation and are not part of the category above.

- 'No referral' (yearly follow-up by optometrist): the absence of pathology classes described above.

The clinical outcome classified by the ophthalmologist was communicated to the partaking optometrist as well as to the patient by dual authentication electronic mail. The patient's GP received a regular letter. Secondary outcome measures were the implementation of the cloud-based referral platform, patient characteristics, time to review and time spent with the software by optometrists and ophthalmologists.

\section{Statistical methods}

Data from the underlying cloud-based data-warehouse (PostgreSQL, PostgreSQL Global Development Group) were exported to an Excel spreadsheet (Microsoft Corporation, Redmond, Washington, DC, USA) for statistical analyses. For all non-parametric data (eg, time to enter data) we reported values as mean, median, IQR and range. Conversely, for all normally distributed data (eg, age, BCVA) mean values are reported with SD.

\section{RESULTS}

\section{Implementation of a cloud-based referral platform}

In May 2017, the cloud-based referral platform was initially introduced in three branches of Rawlings Opticians in the UK as an iPad app only. A web-based interface was launched in April 2018 to improve ease of use and accessibility for the users and another three branches followed. For participating optometrists and ophthalmologists, the data upload interface and review centre are available through two different web links. Over the 10 months observation period, 107 patients met inclusion criteria. These patients were examined by 11 qualified optometrists, who each used the platform to share data with a single consultant ophthalmologist from Moorfields Eye Hospital (DS). Four of the 107 patients were excluded as they had incomplete datasets caused by web browser-related data input issues. Accordingly to the time point of introduction of the referral platform and the size of the branch, most patients were examined at Rawlings Croydon $(n=60 ; 56 \%)$ followed by Chandlers-Ford $(n=23$; $21 \%)$, Winchester $(n=11 ; 10 \%)$, Purley $(n=4 ; 4 \%)$, Alresford $(n=3 ; 3 \%)$ and Caterham $(n=2 ; 2 \%)$. In the same period, we counted in total 1.704 medical retina referrals to our hospital.

\section{Data input, processing and review}

The Big Picture software enables optometrists to submit standardised clinical and retinal imaging data. Please note that all identifiable data provided in online supplemental figures 1 and 2 are not an actual patient for our reference. Any resemblance to a real person living or deceased will be coincidence. When entering clinical history data, the user is met with questions and a range of mutually exclusive yet collectively exhaustive options to select from (online supplemental figure 1). Importantly, the set of questions that need to be addressed change depending on the patient presenting complaint to obtain a comprehensive, patient-centred clinical history. If a patient has previous scans stored within the OCT device, these are processed and uploaded as an imaging history together with the most recent scan. In the review centre, patients are allocated to the worklist of participating ophthalmologist for referral assessment. The review centre provides an overview of the patient's clinical history and data as well as the related retinal images including OCT and colour fundus photography (online supplemental figure 2). To complete the review, a clinical diagnosis and a referral decision must be given for each patient. Data are stored in regional UK servers provided by IBM (Armonk, New York, USA) to comply with national (NHS guidance) and European (General Data Protection Regulation) data safety standards. ${ }^{14}$ A cloud-based data-warehouse using the open source PostgreSQL server reporting software stores and manages the clinical data. Imaging data from the devices can be processed in raw and Digital Imaging and Communications in Medicine formats. 


\begin{tabular}{ll}
\hline Table 1 Patient characteristics & \\
\hline & Mean value \pm SD (range) \\
\hline Age & $66.9 \pm 18.0(23-95)$ \\
\hline Visual acuity right eye (ETDRS letters) & $77.9 \pm 11.8(0-89)$ \\
\hline Visual acuity left eye (ETDRS letters) & $77.7 \pm 12.3(0-89)$ \\
\hline Intraocular pressure right eye (mm Hg) & $13.6 \pm 3.3(7-24)$ \\
\hline Intraocular pressure left eye (mm Hg) & $13.8 \pm 3.6(7-25)$ \\
\hline & Patients (n; \%) \\
\hline Sex & \\
\hline Female & $55(53)$ \\
\hline Male & $47(46)$ \\
\hline Unspecified & $1(1)$ \\
\hline Ethnicity & \\
\hline African & $4(4)$ \\
\hline Caribbean & $2(2)$ \\
\hline Caucasian & $92(89)$ \\
\hline Indian & $2(2)$ \\
\hline Other & $3(3)$ \\
\hline
\end{tabular}

ETDRS, Early Treatment Diabetic Retinopathy Study.

\section{Time measurements}

The software measures the time spent for data input and reviewing, thereby enabling internal evaluation of software usability. The mean overall time for optometrists is $9.2 \mathrm{~min}$ (median: 5.4; IQR: 3.4-8.7) per patient, with 2.1 min (median: 1.7; IQR: 1.1-2.4) spent on clinical history and $6.7 \mathrm{~min}$ (median: 3.6; IQR: 2.1-5.7) on image acquisition. The mean review time for referral refinement by an ophthalmologist was $3.0 \mathrm{~min}$ in total (median: 3.0; IQR: 1.7-3.9), which consisted of $1.0 \mathrm{~min}$ (median: 0.3; IQR: 0.2-1.0), $1.1 \mathrm{~min}$ (median: 0.9; IQR: 0.5-1.5) and 0.9 min (median: 0.8; IQR: 0.3-1.3) for entering clinical history, scans and writing the report. Average time until referral review by an ophthalmologist consultant was 6.4 days (median: 5.2; IQR: 2.9-8.0).

\section{Patient characteristics}

The mean age of the cohort $(n=103)$ was $66.9 \pm 18.0$ years (range: 23-95). More than half of all patients were female $(n=55 ; 53 \%)$ and of Caucasian ethnicity $(\mathrm{n}=92 ; 89 \%)$. At presentation, BCVA was $77.9 \pm 11.8$ and $77.7 \pm 12.3$ ETDRS letters for the right and left eye (range: 0-89), which equates to a mean Snellen fraction of 6/9. Further patient characteristics are summarised in table 1.

The most frequent presentations were unilateral $(n=57$; $57 \%)$ and bilateral $(n=40 ; 39 \%)$ visual deterioration. In cases reporting vision loss ( $n=43 ; 42 \%$ of all presentations), slow onset was more frequent than quick onset; and vision loss was described as mild in $22(51 \%)$, moderate in 16 (37\%) and severe in five (12\%) patients. Only one patient reported ocular pain and visual distortion was reported by 19 patients (18\%) (table 2 ).

\section{Referral refinements by consultant ophthalmologist}

More than half of the patients classified into the referral pathway by the optometrist did not require specialist referral $(n=54$; $52 \%)$. In these cases, the outcome of ophthalmologist assessment was labelled 'no referral necessary', resulting in recommendation for annual follow-up at the optician. Fourteen patients (14\%) were reviewed as urgent and 35 patients (34\%) as routine referrals (figure 1). Vision loss was present in $86 \%$ of urgent referrals, whereas only $37 \%$ in the routine and no referral group reported this symptom. The most common diagnosis observed was dry AMD $(n=34)$, followed by wet AMD $(n=9)$, epiretinal
Table 2 Characteristics of presenting complaint

\begin{tabular}{ll}
\hline & Patients (n; \%) \\
\hline Complaint laterality & $\mathbf{n}=103$ \\
\hline Both eyes & $40(39 \%)$ \\
\hline Right eye & $27(26 \%)$ \\
\hline Left eye & $32(31 \%)$ \\
\hline None & $4(4 \%)$ \\
\hline Eye pain & $\mathbf{n}=103$ \\
\hline Present & $1(1 \%)$ \\
\hline Absent & $102(99 \%)$ \\
\hline Visual distortion & $\mathbf{n}=103$ \\
\hline Present & $19(18 \%)$ \\
\hline Absent & $81(79 \%)$ \\
\hline Unspecified & $3(3 \%)$ \\
\hline Type of vision loss & $\mathbf{n}=103$ \\
No vision loss & $60(58 \%)$ \\
Central vision loss & $3(3 \%)$ \\
\hline Peripheral vision loss & $1(1 \%)$ \\
\hline Distant objects vision loss & $4(4 \%)$ \\
\hline Near objects vision loss & $3(3 \%)$ \\
\hline General vision loss & $32(31 \%)$ \\
\hline If vision loss present & \\
\hline Subjective severity of vision loss & $\mathbf{n}=43$ \\
\hline Mild & $22(51 \%)$ \\
\hline Moderate & $16(37 \%)$ \\
\hline Severe & $5(12 \%)$ \\
\hline Onset of visual complaint & $\mathbf{n}=43$ \\
\hline Quick & $6(14 \%)$ \\
\hline Unspecified & $36(84 \%)$ \\
\hline & $1(2 \%)$ \\
\hline
\end{tabular}

membranes $(n=7)$ and choroidal nevi $(n=7)$. For seven patients, a diagnosis could not be made on clinical history and OCT scans alone (figure 2). Observing the distribution of diagnosis in the 'urgent referral' group $(\mathrm{n}=14)$, the most common diagnosis was wet AMD $(n=9)$, followed by other $(n=3)$, central serous chorioretinopathy (CSCR) $(n=1)$ and optic disc anomalies $(n=1)$. For the 'routine referrals' $(n=35)$ other $(n=11)$ was the most common reason for referral, followed by dry AMD $(n=6)$, ERM $(n=6)$, unknown diagnose $(n=3)$, choroidal naevus $(n=2)$, CSCR $(n=2)$, DR $(n=2)$ optic disc anomalies $(n=2)$ and glaucoma $(n=1)$.

\section{DISCUSSION}

\section{Main findings}

In recognition of its current and impending pressures, the NHS published the Long-Term Plan in January 2019; a 10-year strategy of how the service will transform to meet this challenge. ${ }^{16}$ Herein, there is a call for digital solutions that effectively facilitate communication between patients and healthcare professionals, as well as, between healthcare professionals of different disciplines that collectively coordinate care. The near ubiquity of internet access and internet devices among adults in Great Britain today (90\% and 77\%, respectively, in 2018) have made it possible to deliver positive clinical outcomes outlined in the Long-Term Plan. ${ }^{16}{ }^{17}$ We report the development of such a tool-a cloud-based referral platform that expedites sharing of clinical and imaging data between optometrists and ophthalmologists. Not only general practitioner and ophthalmologist referrals, but also these from urgent care can be triaged into 


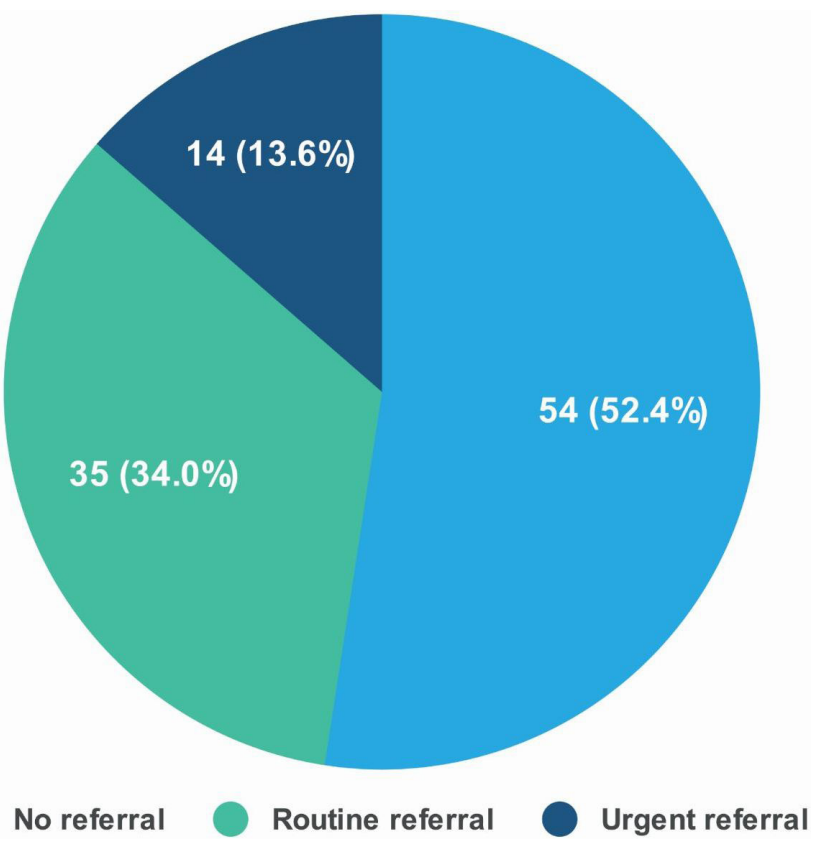

Figure 1 Referral refinement by consultant ophthalmologist where each of the 103 cases were labelled as no referral, routine referral, or urgent referral.

the best suitable clinic setting (virtual or face to face clinics) (figure 3). Using the referral tool took optometrists on average 9 min to gather and send pertinent clinical data of a single case to an ophthalmologist who took on average $3 \mathrm{~min}$ to review it. A reduction in the optometric referral rate of 54\% was observed. As such, this platform yields time-efficient optometric referrals and reduces unnecessary ophthalmologist referrals within the NHS.

\section{Telemedicine in the UK}

Ophthalmology is ideally suited for service provision via telemedicine. A key reason for this is our ability to arrive at diagnoses and clinical decisions in an asynchronous fashion. For example, retinal disease classifications are increasingly reliant on OCT

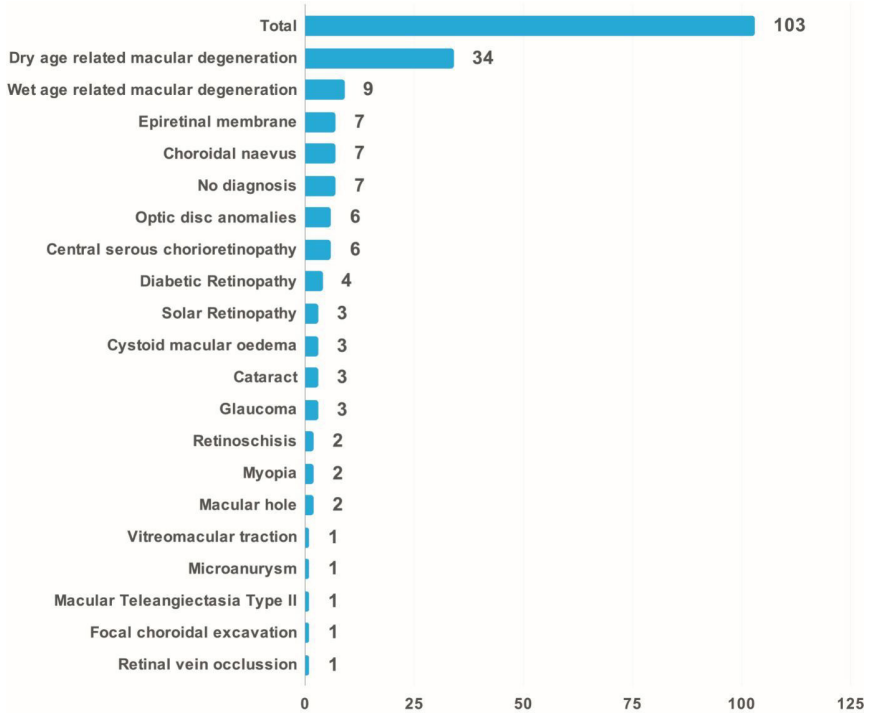

Figure 2 Distribution of clinical diagnoses by consultant ophthalmologist. retinal imaging rather than on the more conventional binocular funduscopy. ${ }^{18}$ There are several proof-of-principle cases where hospital-based teleophthalmology services have been successfully implemented for various retinal conditions, including AMD, DR and retinopathy of prematurity. ${ }^{19}$ A major barrier in teleophthalmology has been overcome in the UK; namely, the high costs that accompany ophthalmic imaging equipment, such as retinal cameras and OCT devices. ${ }^{20}$ In 2017, the largest optical retail chain in the UK (Specsavers, Saint Andrew, UK), which has more than $40 \%$ market share of optometry, announced the national rollout of OCT devices in all 740 practices. ${ }^{21}$ As all major competitors have followed this trend, the UK has the necessary retinal imaging infrastructure and posed to implement a cloud-based teleophthalmology platform as presented in this study.

\section{Unnecessary referrals have an impact on visual outcome}

The unintended consequence of retinal imaging devices' widespread availability at high street opticians is the increased detection of asymptomatic retinal lesions that do not require medical intervention. ${ }^{8}$ With the referral policy defined in the, ${ }^{7}$ these asymptomatic findings become HES referrals and have contributed to the $37 \%$ false positive rate observed in optometric referrals within the NHS. ${ }^{9}$ It is critical to address the high rate of unnecessary referrals as it negatively impacts patient outcomes by overburdening the clinical service and increasing the time for a patient to be seen and receive treatment. Indeed, it has been shown that patients with AMD can lose three lines of vision (ETDRS) if treatment is delayed by a mere 4 weeks. ${ }^{22}$ Similar results are reported in DR where belated detection increased the severity of pathological diabetic retinal changes. ${ }^{23}$ Digital communications platforms that identify urgent referrals with treatable conditions and prioritise them for timely treatment reduce the likelihood of vision loss. ${ }^{24}$ Our cloud-based referral platform enables this and identified 14\% of our cohort as urgent referrals, which were treated accordingly in less than 4 weeks. All nine cases of wet AMD were correctly classified as urgent referrals. In addition to directing clinical services to individuals requiring urgent medical intervention, the platform obviated 54\% of referrals to HES. This is also of high importance in terms of limited available resources as the latest workforce census performed by the Royal College of Ophthalmology identified that two out of three HES' rely on locums to offer needed patient care. ${ }^{25}$ Importantly this also provides a timely and deliverable method of communication between optometrists and ophthalmologists. This dialogue will not only promote improvement in diagnostic quality, but also provides continuous professional development for optometrists using this platform as a reassurance tool for themselves.

\section{Patient centred care}

With 43 patients (41.7\%) AMD was the most common diagnosis made in our patient cohort. For patients with AMD in the UK, access to HES is highly dependent on geographical factors: up to 50 -fold variation in treatment frequency was observed in clusters around specialist centres compared with rural areas. ${ }^{26}$ This implicates a struggle of access to HES for patients with retinal diseases living on the countryside. These patients carry an extra burden compared with the age and gender matched population without AMD. Along with the high age (more than half of the patients being above 75 years old) a majority is affected by visual impairment. Comorbidities are also more common than in the non-AMD population with $55 \%$ suffering from more than five potentially life-threatening diseases. ${ }^{27}$ This highlights the need of patient centred approaches to facilitate access to HES in 


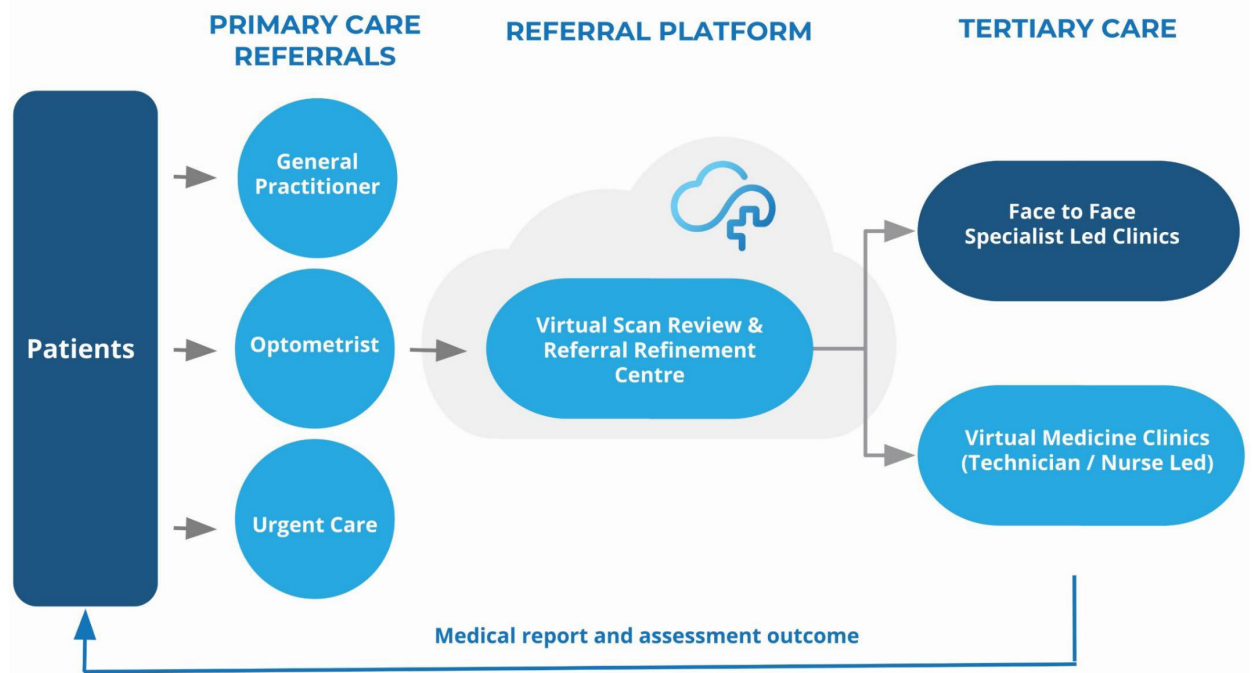

Efficient communication between Patient, Primary and Tertiary Care

Figure 3 Primary care referrals can be triaged into virtual or face to face clinic settings under tertiary care. This decision is made by a specialist within the cloud-based referral platform and based on patient history and scans.

especially this highly vulnerable group of patients. Our telemedicine platform can be seen as a first step in simplifying access to specialist care. Clinical history and imaging data taken by the local optometrists can be accessed by specialists and the number of laborious visits can be avoided in these patients.

\section{Strengths and limitations}

The Big Picture cloud-based referral platform reduces unnecessary HES referrals in the NHS via a time-effective process mediated through a user-friendly interface. It took an average of $6.7 \mathrm{~min}$ (median of $3.6 \mathrm{~min}$ ) to upload the scan data into the platform. Patient satisfaction and acceptability of healthcare interventions play a vital role in whether patients engage with novel services. ${ }^{28}$ Although this was not the scope of this study, we recognise that patient satisfaction is important and must be evaluated while upscaling telemedicine platforms within the NHS. Already available data suggests safety for virtual clinic settings for certain conditions. ${ }^{29}{ }^{30}$ We are presently unable to report on the outcome of our 'non-referral' group yet, which is followed up by optometrists and future studies will evaluate patient safety in a teleophthalmology based referral platform. Another issue is the limitation of $45^{\circ}$ colour fundus pictures to the posterior pole. Peripheral retinal changes as seen in UWFI might be missed. Independently of the clinic setting (virtual or consultant led medical retina clinic), the full spectrum of retinal imaging modalities is available. ${ }^{31}$

\section{Future applications and economic impact}

It has been shown that artificial intelligence can be used to develop algorithms that automatically detect retinal diseases, for example, AMD and DR. ${ }^{32}$ The first algorithm to classify severity of DR received Federal Drug Administration (FDA) approval in the USA in 2018. ${ }^{33}$ Tools for automatic OCT pattern recognition and referral decision-making have already been published and could be integrated into a cloud-based referral platform. ${ }^{34}$ This progress in medicine might simplify the widespread use of cloudbased teleophthalmology platforms in the future.

With current tariffs for professional first attendance consultations ranging from $£ 139$ to $£ 175$ and nearly 8 million outpatient HES appointments yearly, we suspect a possible health economic impact of a cloud-based referral platform. ${ }^{435}$ A national rollout could reduce referrals to retinal HES and thereby cause direct cost savings to the NHS, even after factoring in technology and staffing costs. A separate study assessing the health economic impacts of the cloud-based telemedicine services in eye care is being planned.

\section{CONCLUSION}

In this study we report the first results of using a cloud-based referral platform within the UK and demonstrated that 54\% of referrals to the HES could have been avoided. As the NHS faces increasing demand for service provision, innovations that enhance the digital maturity of secondary service healthcare professionals can further optimise the performance from limited resources.

Correction notice This paper has been amended since it was published Online First. The authors noticed there was a mistake with the affiliations and these have now been amended.

Acknowledgements The authors would like to thank Lauren Stafford for her effort in improving our figures, Mirette Gerges for her help with the data analysis and Duncan Edwards for his technical support.

Contributors All listed authors contributed to the conception or design of the work; or the acquisition, analysis, or interpretation of data for the work; drafted or revised the work critically for important intellectual content; and finally approved this version to be published and agreed to be accountable for all aspects of the work in ensuring that questions related to the accuracy or integrity of any part of the work are appropriately investigated and resolved. CK and DS are responsible for the overall content as guarantors.

Funding The authors have not declared a specific grant for this research from any funding agency in the public, commercial or not-for-profit sectors.

Competing interests $K B$ reports grants from Bayer $A G$, personal fees from Alimera, from Allergan, outside the submitted work; PAK reports other from Big Picture Eye Health, during the conduct of the study; personal fees from DeepMind, personal fees from Optos, personal fees from Novartis, personal fees from Bayer, personal fees from Allergan, personal fees from Heidelberg Engineering, personal fees from Topcon, personal fees from Carl Zeiss Meditec, personal fees from Haag Streit, personal fees from Santen, grants from National Institute for Health Research, grants from Fight For Sight UK, outside the submitted work; TM reports other from Big Picture Medical, outside the submitted work; In addition, TM has a patent 2016265973 pending; KK reports personal fees from Big Picture Eye Health, during the conduct of the study; grants and personal fees from Novartis Pharma, grants and personal fees from Bayer Pharma, personal fees from Zeiss, personal 
fees from Allergan, personal fees from Alcon, personal fees from Google Deepmind, AD has nothing to disclose; outside the submitted work; DS reports other from Big Picture Eye Health, during the conduct of the study; personal fees from Allergan, personal fees from Novartis, personal fees from Bayer, personal fees from Big Picture Eye Health, personal fees from Haag Streit, outside the submitted work; no other relationships or activities that could appear to have influenced the submitted work.

Patient consent for publication Not required.

Provenance and peer review Not commissioned; externally peer reviewed.

Data availability statement Data are available upon request.

Open access This is an open access article distributed in accordance with the Creative Commons Attribution Non Commercial (CC BY-NC 4.0) license, which permits others to distribute, remix, adapt, build upon this work non-commercially, and license their derivative works on different terms, provided the original work is properly cited, appropriate credit is given, any changes made indicated, and the use is non-commercial. See: http://creativecommons.org/licenses/by-nc/4.0/.

ORCID iDs

Christoph Kern http://orcid.org/0000-0002-9699-9255

Karsten Kortuem http://orcid.org/0000-0001-9442-0708

\section{REFERENCES}

1 Wong WL, Su X, Li X, et al. Global prevalence of age-related macular degeneration and disease burden projection for 2020 and 2040: a systematic review and metaanalysis. Lancet Glob Health 2014;2:e106-16.

2 Hendrick AM, Gibson MV, Kulshreshtha A. Diabetic retinopathy. Prim Care 2015;42:451-64.

3 Ogurtsova K, da Rocha Fernandes JD, Huang Y, et al. IDF diabetes atlas: global estimates for the prevalence of diabetes for 2015 and 2040. Diabetes Res Clin Pract 2017; 128:40-50.

4 Hospital Outpatient Activity. Nhs digital. NHS digital., 2017-18. Available: https:// digital.nhs.uk/data-and-information/publications/statistical/hospital-outpatientactivity/2017-18 [Accessed 1 Nov 2018].

5 Resnikoff S, Felch W, Gauthier T-M, et al. The number of ophthalmologists in practice and training worldwide: a growing gap despite more than 200000 practitioners. $\mathrm{Br}$ J Ophthalmol 2012;96:783-7.

6 How often can I have a free NHS eye test? Available: https://www.nhs.uk/commonhealth-questions/nhs-services-and-treatments/how-often-can-i-have-a-free-nhs-eyetest/ [Accessed 21 Jan 2019].

7 Participation E, Act O. Published online first: 16 November 1989., 1989. Available: https://www.legislation.gov.uk/ukpga/1989/44/contents [Accessed 1 Nov 2018]

8 Quinn N, Csincsik L, Flynn E, et al. The clinical relevance of visualising the peripheral retina. Prog Retin Eye Res (Published Online First: 10 October 2018).

9 Cameron JR, Ahmed S, Curry P, et al. Impact of direct electronic optometric referral with ocular imaging to a hospital eye service. Eye 2009;23:1134-40.

10 Cellan-Jones R. NHS. Google - and a problem with sharing. BBC News, 2016. Available: https://www.bbc.com/news/technology-36722152 [Accessed 2 Nov 2018]

11 Gregori NZ, Feuer W, Rosenfeld PJ. Novel method for analyzing Snellen visual acuity measurements. Retina 2010;30:1046-50.

12 England NHS. Nhs England model contracts and contract variations: general ophthalmic services. Available: https://www.england.nhs.uk/publication/modelcontracts-and-contract-variations-general-ophthalmic-services/ [Accessed $8 \mathrm{Apr}$ 2019].

13 England NHS. Nhs England referral to treatment. Available: https://www.england.nhs. uk/rtt/ [Accessed 31 Jan 2019].

14 NHS Digital. Health and social care cloud security - good practice guide - NHS Digital. Available: https://digital.nhs.uk/data-and-information/looking-after-information/ data-security-and-information-governance/nhs-and-social-care-data-off-shoring-andthe-use-of-public-cloud-services/health-and-social-care-cloud-security-good-practiceguide [Accessed 24 Jan 2019].

15 EUR-Lex - 32016R0679 - EN - EUR-Lex. Available: https://eur-lex.europa.eu/legalcontent/EN/TXT/?uri=celex\%3A32016R0679 [Accessed 24 Jan 2019].

16 Nhs long term plan. Online version of the NHS long term plan. Available: https:// www.longtermplan.nhs.uk/online-version/ [Accessed 18 Feb 2019].

17 Office for National Statistics. Internet access - households and individuals, great Britain. Available: https://www.ons.gov.uk/peoplepopulationandcommunity/househol dcharacteristics/homeinternetandsocialmediausage/bulletins/internetaccesshouseh oldsandindividuals/2018\#9-out-of-10-households-have-internet-access (accessed 7 Feb 2019).

18 Eladawi N, Elmogy MM, Ghazal M, et al. Classification of retinal diseases based on OCT images. Front Biosci 2018;23:247-64.

19 Chee R-I, Darwish D, Fernandez-Vega A, et al. Retinal telemedicine. Curr Ophthalmol Rep 2018;6:36-45.

20 Rathi S, Tsui E, Mehta N, et al. The current state of Teleophthalmology in the United States. Ophthalmology 2017;124:1729-34.

21 McCormick E. Oct rollout in every Specsavers announced. Available: https://www.aop. org.uk/ot/industry/high-street/2017/05/22/oct-rollout-in-every-specsavers-announced [Accessed 28 Jan 2019].

22 D'souza Y, Tufail A. The role of telemedicine in improving the referral service for consideration of treatment for age-related macular degeneration in a tertiary referral centre. Acta Ophthalmol Scand 2007:85.

23 Scanlon PH, Aldington SJ, Stratton IM. Delay in diabetic retinopathy screening increases the rate of detection of referable diabetic retinopathy. Diabet Med 2014;31:439-42

24 Khan AA, Mustafa MZ, Sanders R. Improving patient access to prevent sight loss: ophthalmic electronic referrals and communication (Scotland). Public Health 2015;129:117-23.

25 The Royal College of ophthalmologists, United Kingdom, 2018. Workforce census. Available: https://rcophth.ac.uk/publications/workforce-census-2018/[Accessed 8 July 2019].

26 Keenan TDL, Wotton CJ, Goldacre MJ. Trends over time and geographical variation in rates of intravitreal injections in England. Br J Ophthalmol 2012;96:413-8.

27 Zlateva GP, Javitt JC, Shah SN, et al. Comparison of comorbid conditions between neovascular AGE-RELATED macular degeneration patients and a control cohort in the Medicare population. Retina 2007;27:1292-9.

28 Sekhon M, Cartwright M, Francis JJ. Acceptability of healthcare interventions: an overview of reviews and development of a theoretical framework. BMC Health Serv Res 2017;17:88

29 Clarke J, Puertas R, Kotecha A, et al. Virtual clinics in glaucoma care: face-to-face versus remote decision-making. Br J Ophthalmol 2017;101:892-5.

30 Balaskas K, Gray J, Blows P, et al. Management of choroidal naevomelanocytic lesions: feasibility and safety of a virtual clinic model. Br J Ophthalmol 2016;100:665-70.

31 Kern C, Kortuem K, Hamilton R, et al. Clinical outcomes of a hospital-based Teleophthalmology service: what happens to patients in a virtual clinic? Ophthalmol Retina 2019:3:422-8.

32 Matsuba S, Tabuchi H, Ohsugi $H$, et al. Accuracy of ultra-wide-field fundus ophthalmoscopy-assisted deep learning, a machine-learning technology, for detecting age-related macular degeneration. Int Ophthalmol 2019;39:1269-75.

33 Office of the Commissioner. Press Announcements - FDA permits marketing of artificial intelligence-based device to detect certain diabetes-related eye problems. Available: https://www.fda.gov/newsevents/newsroom/pressannouncements/ ucm604357.htm [Accessed 1 Nov 2018].

34 De Fauw J, Ledsam JR, Romera-Paredes B, et al. Clinically applicable deep learning for diagnosis and referral in retinal disease. Nat Med 2018;24:1342-50.

35 NHS Improvement. National tariff payment system. Available: https://improvement. nhs.uk/resources/national-tariff/ [Accessed 11 Apr 2019]. 